\title{
Esophageal Motor Dysfunctions in Gastroesophageal Reflux Disease and Therapeutic Perspectives
}

\author{
Sihui Lin, ${ }^{1,2}$ Hua Li, ${ }^{2}$ and Xiucai Fang ${ }^{1 *}$ \\ ${ }^{I}$ Department of Gastroenterology, Peking Union Medical College Hospital, Chinese Academy of Medical Sciences and Peking Union Medical \\ College, Beijing; China; and ${ }^{2}$ Department of Gastroenterology, The First Affiliated Hospital of Xiamen University, Xiamen, Fujian Province, \\ China
}

Gastroesophageal reflux disease (GERD) is a very common disease, and the prevalence in the general population has recently increased. GERD is a chronic relapsing disease associated with motility disorders of the upper gastrointestinal tract. Several factors are implicated in GERD, including hypotensive lower esophageal sphincter, frequent transient lower esophageal sphincter relaxation, esophageal hypersensitivity, reduced resistance of the esophageal mucosa against the refluxed contents, ineffective esophageal motility, abnormal bolus transport, deficits initiating secondary peristalsis, abnormal response to multiple rapid swallowing, and hiatal hernia. One or more of these mechanisms result in the reflux of stomach contents into the esophagus, delayed clearance of the refluxate, and the development of symptoms and/or complications. New techniques, such as 24-hour pH and multichannel intraluminal impedance monitoring, multichannel intraluminal impedance and esophageal manometry, high-resolution manometry, 3-dimensional highresolution manometry, enoscopic functional luminal imaging probe, and 24-hour dynamic esophageal manometry, provide more information on esophageal motility and have clarified the pathophysiology of GERD. Proton pump inhibitors remain the preferred pharmaceutical option to treat GERD. The ideal target of GERD treatment is to restore esophageal motility and reconstruct the antireflux mechanism. This review focuses on current advances in esophageal motor dysfunction in patients with GERD and the influence of these developments on GERD treatment.

(J Neurogastroenterol Motil 2019;25:499-507)

\section{Key Words}

Esophageal motility disorders; Esophagogastric junction; Gastroesophageal reflux; Manometry; Pharmaceutical preparations

\section{Introduction}

Reflux of gastric contents into the esophagus induces esophageal symptoms of regurgitation and heartburn, and potentially, extraesophageal symptoms. ${ }^{1}$ In some patients with gastroesophageal reflux disease (GERD), frequent and severe reflux may result in reflux esophagitis. Available data indicate that GERD results from multiple predisposing factors in upper gastrointestinal dysmotility, which result in increased reflux and decreased defenses against the refluxate. The association of GERD with acid is actually the dislocation of acid secondary to motility disorders. Increased transient lower esophageal sphincter relaxation (TLESR), hypotensive lower esophageal sphincter (LES) or diaphragmatic crural dysfunction,

Received: April 10, 2019 Revised: None Accepted: July 20, 2019

() This is an Open Access article distributed under the terms of the Creative Commons Attribution Non-Commercial License (http://creativecommons. org/licenses/by-nc/4.0) which permits unrestricted non-commercial use, distribution, and reproduction in any medium, provided the original work is properly cited.

*Correspondence: Xiucai Fang, MD Department of Gastroenterology, Peking Union Medical College Hospital, Chinese Academy of Medical Sciences and Peking Union Medical College, 1\# Shuaifuyuan, Dongcheng District, Beijing 100730, China

Tel: +86-10-6915-6892, +86-1343-913-6086, Fax: +86-10-6915-1963, E-mail: fangxiucai2@aliyun.com 
anatomical defects in the esophagogastric junction (EGJ), ineffective esophageal motility (IEM), abnormal esophageal bolus transport, and abnormal responses to multiple rapid swallowing (MRS) are closely associated with GERD. ${ }^{2-5}$ Recently, new techniques to detect esophageal functional defects, such as 24-hour $\mathrm{pH}$ and multichannel intraluminal impedance (MII) monitoring, MII and esophageal manometry (MII-EM), high-resolution manometry (HRM), 3-dimensional HRM, enoscopic functional luminal imaging probe (EndoFLIP), and 24-hour dynamic esophageal manometry have improved our understanding of the pathogenesis of GERD and provided the basis for developing comprehensive and effective treatment programs. In this article, we reviewed recent advances in our understanding of esophageal motility dysfunction in GERD and discussed GERD therapeutic perspectives.

\section{Abnormal Motility in Gastroesophageal Re- flux Disease and Its Association With Reflux Events}

The pathophysiological mechanisms of GERD include impaired anti-reflux defense and increased injury to the esophageal mucosa by refluxed contents. The former includes disruption of the anti-reflux barrier at the EGJ, decreased ability of the esophagus in clearing the refluxed contents, and reduced resistance of the esophageal mucosa to the refluxate.

\section{Disruption of the Anti-reflux Barrier at the Esophagogastric Junction}

The EGJ includes several structures, including the LES, diaphragmatic crura, and phrenicoesophageal ligament, which form an anti-reflux barrier. Decreased function of the EGJ anti-reflux barrier manifests primarily as follows.

\section{Frequent transient lower esophageal sphincter relax- ation}

When swallowing, the EGJ acts as a one-way valve, allowing food or liquid to enter the stomach from the esophagus and effectively prevents reflux of the gastric contents. TLESR is not associated with swallowing, which differs from LES relaxation caused by swallowing. The duration of TLESR is more than 10 seconds, which is longer than that of swallowing-induced LES relaxation (typically lasting 6-8 seconds), and there is no pharyngeal swallowing signal 4 seconds before and 2 seconds after LES relaxation. ${ }^{6}$ TLESR spontaneously appears at either relatively stable LES pressures or after LES relaxation during normal swallowing. TLESR allows gas to move into the esophagus from the proximal stomach while preventing reflux of gastric contents. If TLESRs occur frequently, gastric contents may escape and reflux into the esophagus, especially within 15 minutes after eating (when there is an acid pocket), and gastric juice near the cardia may leak backwards into the esophagus and increase the incidence of postprandial reflux events. $^{\text {? }}$

The incidence of TLESR in GERD patients is more than two times that of healthy people. ${ }^{4}$ Other studies demonstrated that patients with GERD do not have more frequent TLESRs than healthy or asymptomatic controls, but instead, TLESRs in GERD patients are more likely to be associated with acid reflux. ${ }^{8-10}$ Pandolfino et $\mathrm{al}^{7}$ studied TLESR using HRM and found that TLESRinduced EGJ opening was caused by LES relaxation, inhibited crural contraction, esophageal shortening, and increased gastric pressure. Also, in cases of incomplete TLESR, LES elevation is seen with HRM manometry, and ultrasonography shows esophageal muscle thickening $2 \mathrm{~cm}$ above the LES, indicating contraction of the esophageal longitudinal muscle, which may be the main cause of TLESR. ${ }^{11}$

\section{Hypotensive lower esophageal sphincter, crural dia- phragmatic dysfunction, or increased esophagogastric junction compliance without abnormal anatomy}

LES pressure in normal individuals is lowest after eating and highest at night. Even if the LES is relaxed, the pressure remains slightly higher than the intragastric pressure, to prevent reflux. This is important when the pressure difference between the stomach and esophagus is maximal (such as at end-inspiration), and gastroesophageal reflux occurs when the resting LES pressure is abnormally low or the intragastric pressure is high. ${ }^{12}$ LES pressure at rest is maintained between $10-30 \mathrm{mmHg}$ in healthy people. The LES resting pressure of patients with reflux esophagitis is significantly lower than that of healthy control ${ }^{13}$ or patients with non-erosive reflux disease (NERD), and the length of the LES is also shorter. ${ }^{3}$ In obese patients with GERD, the intragastric pressure and mean gastroesophageal pressure gradient are significantly increased compared with those with a healthy body mass index, which also provides a perfect scenario for reflux. ${ }^{14}$

At end-expiration, EGJ pressure is maintained mainly by the LES, and increased EGJ pressure during inspiration results from the strengthening effect of the crural diaphragm on the LES. Sun et $\mathrm{al}^{15}$ found that crural diaphragmatic pressure in patients with GERD at resting was lower than that of healthy controls. The authors also found a significant increase in crural diaphragmatic pres- 
sure during deep diaphragmatic breathing both for GERD patients and healthy subjects. With the development of HRM, a parameter similar to the distal contraction integral (DCI) concept has been proposed for measuring EGJ barrier function. This new parameter, the EGJ-contractile integral (EGJ-CI), involves calculating EGJ vigor (including dual contribution by the LES and diaphragmatic crura) during three respiratory cycles, then dividing by the value of the length of time of the cycles. ${ }^{16}$ Patients with GERD had a lower median EGJ-CI value compared with patients with functional heartburn. ${ }^{17}$ Patients with GERD with a defective EGJ-CI more frequently had positive reflux in impedance-pH monitoring or esophageal mucosal lesions at endoscopy than did patients with normal EGJ-CI values. ${ }^{17}$ This metric partially predicts abnormal esophageal acid exposure time and symptomatic outcome following anti-reflux therapy. ${ }^{18}$

Increased EGJ compliance is another pathophysiological abnormality in many patients with GERD. ${ }^{19,20}$ Excessive EGJ compliance allows more gastric contents to reflux into the esophagus and increases the frequency of TLESR, which is elicited by proximal gastric distention. $^{21-23}$ EndoFLIP, which evaluates EGJ compliance during endoscopy, has shown that patients with GERD exhibited 2-3 fold increase in EGJ distensibility compared with controls, especially at $20-\mathrm{mL}$ to $30-\mathrm{mL}$ distention volumes. ${ }^{24,25}$

\section{Abnormal esophagogastric junction local anatomy}

With anatomical disruption of the EGJ or hiatal hernia, relaxation of the phrenicoesophageal ligament, which is responsible for fixing the GEJ onto the diaphragm, makes a portion of the stomach move superior to the diaphragm. In such cases, 2 high-pressure zones are seen during esophageal HRM. Studies show that HRM has a high sensitivity of $92 \%$ and a specificity of $95 \%$ for detecting hiatal hernia. ${ }^{26}$ The Chicago classification describes 3 subtypes of EGJ based on the separation distance between the diaphragmatic crura and the LES: type I, no separation between the LES and diaphragmatic crura; type II, minimal separation $(>1$ and $<2$ $\mathrm{cm}$ ); and type III, $\geq 2 \mathrm{~cm}$ of separation. ${ }^{27} \mathrm{~A}$ significant increase in esophageal acid exposure time, total number of reflux episodes, DeMeester score, and positive reflux-symptom association are seen when the separation between the LES and diaphragmatic crura widens (type III EGJ morphology). ${ }^{28,29}$ EGJ types I and II, with complete or partial overlap between the LES and diaphragmatic crura, have increased inspiratory pressure at the diaphragmatic crura. In contrast, patients with EGJ type III have complete LESdiaphragmatic crura separation and reduced inspiratory pressure. ${ }^{30}$ Also, hiatal hernia affects the location of the acid pocket, extending the duration of esophageal acid exposure. Unlike in healthy individuals, the acid pocket in patients with GERD and hiatal hernia is located superior to the diaphragm or in a hernia sac, during TLESR. This phenomenon is more prominent in patients with GERD and large hernia sacs, and reflux events are seen more frequently in these patients during TLESR. ${ }^{12,31}$ Obese patients are more likely to have EGJ disruption (leading to hiatal hernia). ${ }^{12}$

\section{Impaired Esophageal Clearance of the Refluxate}

\section{Ineffective primary peristalsis}

Studies using conventional water-perfused manometry and HRM have shown that IEM is the most common esophageal motility disorder. Previous studies divided IEM into lack of peristalsis, invalid contraction, synchronous contraction, and lowamplitude contraction. ${ }^{32}$ The newly-revised Chicago classification for esophageal motility disorders divided IEM into weak peristalsis (DCI < $450 \mathrm{mmHg} \cdot \mathrm{sec}^{\circ} \mathrm{cm}$ ) and no peristalsis (DCI < $100 \mathrm{mmHg} \cdot \mathrm{sec}^{\cdot} \mathrm{cm}$ ) based on DCI in the HRM data. ${ }^{27}$ Patients with reflux esophagitis and those with NERD both have IEM although the incidence of IEM in patients with reflux esophagitis is higher than in patients with NERD (29\% vs $15 \%$, respectively; $P=0.030) .{ }^{33}$ IEM is more often associated with acid exposure, abnormal weakly-acidic reflux, and long-term acid reflux in patients with refractory GERD, and IEM severity parallels the degree of esophageal mucosal damage. Patients with reflux esophagitis had a lower DCI than patients without reflux esophagitis in one study (558 $\mathrm{mmHg} \cdot \mathrm{sec} \cdot \mathrm{cm}$ vs $782 \mathrm{mmHg} \cdot \mathrm{sec} \cdot \mathrm{cm}$, respectively; $P=0.045) .^{34}$ To distinguish the contraction pattern from contractile vigor, the Chicago classification proposed small breaks $(<3 \mathrm{~cm})$ and large breaks $(>5 \mathrm{~cm})$ in the $20-\mathrm{mmHg}$ isobaric contour. The latter is more common in patients with GERD, who have a pathological number of large breaks assessed by HRM, and are characterized by having a significantly prolonged reflux clearance in the supine position and higher esophageal acid exposure time. ${ }^{35}$

\section{Abnormal secondary peristalsis}

Primary esophageal peristalsis is mainly responsible for transporting the bolus inside the esophagus whereas secondary peristalsis clears the refluxate and swallowed food residue to empty the esophagus. Secondary peristalsis can be initiated by a variety of stimuli in the esophagus such as gas, balloon-dilatation, or water perfusion. Bolus-induced peristalsis can be initiated by intrinsic neural programs independent of vagal activity, but is influenced by vagal activity. ${ }^{36}$ Studies evaluating secondary peristalsis often involve 
injecting gas or liquid, first slowly then quickly, into the esophagus. The amount of gas or liquid inducing secondary peristalsis at different speeds is recorded separately, and the effectiveness of the secondary peristaltic response and related pressure parameters are identified. ${ }^{37-40}$ During rapid injection of gas or liquid, most patients with GERD have an initiation deficit for secondary peristalsis. ${ }^{41}$ Patients with IEM and abnormal bolus transport require more gas to induce secondary peristalsis compared with healthy individuals, patients with IEM and normal bolus transport. This higher gas requirement may be caused by disturbances in sensory vagal pathways affecting motor function. During slow injection of gas, the incidence of failed secondary peristalsis in patients with IEM and abnormal bolus transport, and in patients with IEM and normal bolus transport, are higher compared with healthy individuals (57\% vs $0 \%$, respectively; $P=0.040 ; 27 \%$ vs $0 \%$, respectively; $P<$ $0.001) .{ }^{39}$ With bolus-induced peristalsis, the contraction amplitude may depend largely on the bolus size; measuring contraction force in response to balloon distention can accurately measure sensory dysfunction. $^{42}$

The best way to evaluate secondary motility disorders involves simultaneously monitoring reflux events and motility. A recent study found that when long-duration acid reflux occurred, effective secondary peristalsis in response to long-duration reflux episodes was significantly decreased in patients with refractory GERD compared with those with non-refractory GERD. ${ }^{43}$ With decreased esophageal ability to clear debris, reflux occurs repeatedly, the duration of esophageal acid exposure increases, refluxed contents damage the esophageal mucosa, esophagitis and related complications occur. $^{44}$

\section{Abnormal esophageal bolus transport}

Bolus transport is another method of assessing esophageal motility. Comparing patients with functional heartburn and with healthy individuals, patients with GERD often have more significantly abnormal bolus transport, which is represented by incomplete bolus transport and extended total bolus transport time. ${ }^{45} \mathrm{MII}-\mathrm{EM}$ can evaluate esophageal motility and bolus transport simultaneously and identify abnormal bolus transport during swallowing. During MII-EM, 3 abnormal modes are seen in patients with GERD. The first is invalid transport, in which the bolus transport signal disappears completely, bolus transport is totally interrupted, resistance value decreases slightly, and there is no peristaltic wave in the esophagus. The second abnormal mode is extended transport, in which transport signals in the proximal esophagus are seen and transport signals in the middle and distal esophagus are extended in a typical stepwise pattern. The corresponding peristaltic mode often has several pathological forms, such as weak contraction or synchronous peristalsis. The third abnormal mode is mixed transport with two-part signals. The first part is a signal that can be detected when swallowing a bolus, and the second part includes a peristaltic wave while there is no second swallowing, and which occurs within 4 seconds after the first signal. However, the corresponding peristaltic model remains unclear. ${ }^{46}$

Abnormal bolus transport is also often related to the severity of GERD. Savarino et $\mathrm{al}^{47}$ found that the incidences of complete liquid bolus and viscous bolus transports in reflux esophagitis patients were significantly lower than those in patients with either NERD or functional heartburn. The duration of bolus transport in patients with reflux esophagitis was also longer than that in patients with either NERD or functional heartburn.

IEM is assumed to be associated with ineffective bolus transport. However, this motor pattern, although classified as "ineffective," does not indicate no bolus movement through the esophagus. In a study of 70 patients with IEM, $48 \%$ of ineffective liquid swallows and $38 \%$ of ineffective viscous swallows showed complete bolus transit based on impedance measurements. ${ }^{48}$ Nguyen et $\mathrm{al}^{49}$ showed that the proportion of liquid boluses cleared was directly related to contraction amplitude and did not increase significantly above a threshold of $22 \mathrm{mmHg}$ in the mid-esophagus and 30 $\mathrm{mmHg}$ in the distal esophagus. Therefore, ineffective bolus transit cannot be determined by manometry alone. MII-EM may discriminate patients suffering from impaired bolus clearance from patients with disordered esophageal perception.

\section{Abnormal multiple rapid swallowing}

MRS testing to assess peristaltic reserve has been advocated as an adjunct to standard high resolution manometry. ${ }^{50}$ During traditional water-perfused manometry or pressure measurement combined with impedance testing, 10 independent swallows are often required, and the time interval between 2 swallows is 20-30 seconds. MRS involving 5 swallows ( $2 \mathrm{~mL}$ each) in rapid sequence (separated by 2-3 seconds) occurs often during drinking or eating in daily life; therefore, current detection methods do not comprehensively reflect actual esophageal motility. MRS may depress the central and peripheral nervous system and inhibit esophageal smooth muscle contraction and cause complete and persistent LES relaxation. The last swallow of the MRS process is followed by a series of more powerful esophageal contractions and LES contractions after relaxation. ${ }^{51}$ A normal MRS response requires not only complete inhibitory and excitatory mechanisms to regulate coordi- 
nation between the esophageal body and the LES, but also requires esophageal smooth muscle integrity to respond to the strong stimulation at the end of MRS. ${ }^{50,52}$ The MRS response was abnormal in $65 \%$ of patients with IEM in one study. ${ }^{50} \mathrm{~A}$ more recent study ${ }^{53}$ showed that post MRS contractile DCI and the preoperative ratio of esophageal peristalsis DCI to wet swallowing (WS) DCI (MRS/ WS) were lower in impedance- and $\mathrm{pH}$ test-positive patients compared with negative patients. Post-MRS contractile DCI and the MRS/WS ratio were also correlated with esophageal acid exposure time, baseline impedance values, and post-reflux swallowinduced peristaltic wave index..$^{53}$ Low baseline impedance values were related to impaired esophageal mucosal integrity and increased sensitivity to acid stimulation in patients with functional heartburn. ${ }^{54}$ The post-reflux swallow-induced index, as a measure of impaired chemical clearance, is a primary pathophysiological mechanism in GERD.$^{55}$ The value of assessing DCI ratio is controversial, and investigators are recommended to simply use contraction amplitude $<450 \mathrm{mmHg} \cdot \mathrm{sec} \cdot \mathrm{cm}$ as a benchmark for ineffective motility. It is likely that manometry with additional MRS testing can better evaluate clinically relevant motor dysfunction, better assess ineffective bolus transit, and better predict treatment efficacy. ${ }^{56}$ Strong results following MRS testing in patients with IEM suggests peristaltic reserve and may predict success with prokinetic treatment.

We summarized the esophageal motor dysfunctions and link to reflux in GERD patients in Table 1.

\section{Therapeutic Perspectives in Esophageal Motility Disorders for Patients With Gastro- esophageal Reflux Disease}

The Asia-Pacific consensus on GERD emphasizes that proton pump inhibitors (PPI) remain the preferred pharmaceutical in GERD treatment. ${ }^{57}$ Therapy to suppress acid production reduces aggressive risk factors in GERD treatment but cannot improve motility dysfunction(s) causing reflux, such as TLESR, low LES pressure, or reduced clearance ability. Improving motility is an essential component of GERD treatment (Table 2).

\section{Lifestyle and Dietary Modifications}

Obesity may weaken the anti-reflux barrier at the EGJ and is relevant to GERD pathogenesis. ${ }^{57,58}$ Weight loss is considered an appropriate lifestyle modification to improve GERD symptoms by lowering intragastric pressure and reducing the reflux frequency. However, it remains unknown whether weight loss can reverse ana-

Table 1. Esophageal Motility Disorders and Link to Reflux in Gastroesophageal Reflux Disease Patients

\begin{tabular}{|c|c|c|c|}
\hline \multicolumn{2}{|c|}{ Esophageal motility disorders } & \multirow{2}{*}{ Detection method } & \multirow{2}{*}{ Link to reflux } \\
\hline Category & Abnormality & & \\
\hline \multirow{8}{*}{$\begin{array}{l}\text { Anti-reflux barrier } \\
\text { at EGJ }\end{array}$} & Frequent TLESR & HRM & Postprandial acid reflux $\uparrow^{7}$ \\
\hline & Hypotensive LES & HRM/conventional manometry & Reflux esophagitis $\uparrow^{13}$ \\
\hline & Shorter length of LES & HRM/conventional manometry & Reflux esophagitis $\uparrow^{3}$ \\
\hline & EGJ-CI/lower rural diaphragmatic & HRM/conventional manometry & Acid exposure $\uparrow$ \\
\hline & pressure & & Erosive mucosal lesion $\uparrow^{17}$ \\
\hline & Increased EGJ compliance & EndoFLIP & More reflux ${ }^{21-23}$ \\
\hline & Hiatal hernia & HRM & Acid exposure time $\uparrow$ \\
\hline & & & DeMeester score $\uparrow^{28,29}$ \\
\hline \multirow{9}{*}{$\begin{array}{l}\text { Esophageal body } \\
\text { motility }\end{array}$} & Ineffective primary peristalsis & HRM/dynamic manometry & Acid, weakly-acidic reflux $\uparrow$ \\
\hline & & & Long-term acid reflux $\uparrow$ \\
\hline & & & Esophageal mucosal damage $\uparrow^{33-35}$ \\
\hline & Decreased effective secondary & Pressure and $\mathrm{pH}$-impedance dynamic & Common in refractory GERD \\
\hline & peristalsis & monitoring & Response to long acid reflux $\downarrow$ \\
\hline & & & Erosive esophagitis and complication $\uparrow^{43,44}$ \\
\hline & $\begin{array}{l}\text { Long duration of esophageal bolus } \\
\text { transport }\end{array}$ & MII/MII-EM & Reflux esophagitis $\uparrow^{47}$ \\
\hline & Abnormal multiple rapid swallowing & HRM & Acid exposure time $\uparrow^{53}$ \\
\hline & & & Predict efficacy of prokinetics ${ }^{56}$ \\
\hline
\end{tabular}

EGJ, esophagogastric junction; TLESR, lower esophageal sphincter relaxation; LES, lower esophageal sphincter; EGJ-CI, esophagogastric junction-contractile integral; HRM, high-resolution manometry; EndoFLIP, enoscopic functional luminal imaging probe; MII, multichannel intraluminal impedance; MII-EM, multichannel intraluminal impedance and esophageal manometry; GERD, Gastroesophageal reflux disease. 
Table 2. The Possible Therapeutic Targets of Dysmotilities in Gastroesophageal Reflux Disease Patients

\begin{tabular}{|c|c|c|}
\hline Dysmotilities & Therapeutic methods & Validated/potential efficacies \\
\hline Frequent TLESR & Acotiamide & $\begin{array}{l}\text { Improve gastric accommodation } \\
\text { Number of TLESRs } \downarrow^{64}\end{array}$ \\
\hline EGJ-CI/lower rural diaphragmatic pressure & Diaphragm biofeedback & $\begin{array}{l}\text { Crural diaphragm tension } \uparrow \\
\text { EGJ pressure } \uparrow \\
\text { PPI usage } \downarrow^{59}\end{array}$ \\
\hline Hypotensive LES & Prokinetics & $\begin{array}{l}\text { LES pressure } \uparrow \\
\text { Reflux episodes } \downarrow^{60,61}\end{array}$ \\
\hline Ineffective primary peristalsis & Prokinetics & Combined with PPI for severe GERD ${ }^{62}$ \\
\hline Decreased effective secondary peristalsis & Mosapride & Improve secondary peristalsis ${ }^{37}$ \\
\hline Overlap with delayed gastric empty & Prokinetics & Combined with PPI \\
\hline Presumed high intragastric pressure & Weight loss in obesity & $\begin{array}{l}\text { Reflux frequency } \downarrow \\
\text { Enhance EGJ } ?^{57,58}\end{array}$ \\
\hline $\begin{array}{l}\text { Co-exist with hiatal hernia and/or failed to } \\
\text { medical therapy }\end{array}$ & Fundoplication & Normalized of ineffective peristalsis? Enhance LES pressure ${ }^{65,66}$ \\
\hline
\end{tabular}

TLESR, lower esophageal sphincter relaxation; EGJ-CI, esophagogastric junction-contractile integral; LES, lower esophageal sphincter; EGJ, esophagogastric junction; PPI, proton pump inhibitors; GERD, gastroesophageal reflux disease.

tomical disruption of the EGJ. Sun et $\mathrm{al}^{59}$ reported that diaphragm biofeedback training for 30 minutes in the fasting state in the initial 8 weeks combined with rabeprazole, and then training 20 minutes twice a day in the fasting state at home for 6 months with acid depression on demand therapy, diaphragm biofeedback increased crural diaphragm tension and GEJ pressure significantly at 8 weeks evaluation, but without change in LES pressure, long term training decreased the usage of acid depression during 6 months follow-up.

\section{Medical Treatment Options}

Currently, prokinetic agents used to treat GERD include dopamine receptor antagonists (metoclopramide and domperidone), serotonin receptor agonists (mosapride, tegaserod, and prucalopride), and prokinetic drugs with dual modes of action (itopride and trimebutine maleate). ${ }^{60,61}$ Prokinetic drugs can accelerate gastric emptying, increase resting LES pressure, or enhance esophageal clearance of the refluxed contents. Ndraha ${ }^{62}$ performed a randomized double-blind study to compare the efficacy of 2 weeks' administration of a PPI (omeprazole, $20 \mathrm{mg}$ per os every 12 hours) and the combined administration of a PPI and a prokinetic (domperidone, $10 \mathrm{mg}$ per os every 8 hours), and found that combination therapy resulted in a significant improvement in reflux symptoms compared with patients receiving the PPI alone (reflux symptom score: $4.6 \pm 3.3$ vs $7.5 \pm 5.9$, respectively; $P=0.020)$. A separate study showed that mosapride decreased the threshold value of the gas volume required for inducing secondary peristalsis to improve the efficacy of secondary peristalsis. ${ }^{37}$ Prucalopride, a selective high- affinity serotonin receptor agonist, reduced the number of persisting or weakly and/or non-acid reflux episodes in 4 patients with constipation. ${ }^{63}$ It is important to note that the potencies of some PPIs decrease at low $\mathrm{pH}$, and delayed gastric emptying may affect their acid-suppression ability; therefore, improved gastric motility can promote PPI potency. Combined prokinetic therapy should be considered for patients with significant esophageal motility disorders, delayed gastric emptying, and severe GERD. Acotiamide, a novel prokinetic, is a selective acetylcholinesterase inhibitor and enhances the actions of cholinergic neurons. It was observed that acotiamide can reduce TLESRs and enhancing esophageal bolus clearance in healthy subjects. ${ }^{64}$ These observed effects would be favorable for treating patients with GERD and future research is needed.

\section{Endoscopic or Surgical Treatment}

Anti-reflux surgery is the final choice for patients with GERD and unsatisfactory outcomes after conservative treatment. Motility in the esophageal body is an indicator predicting outcomes following fundoplication. Seo et $\mathrm{al}^{65}$ reported that the presence of absent esophageal motility did not affect the outcome of fundoplication. Specifically, there were no significant differences between patients with absent esophageal motility and those with normal esophageal motility before surgery for dysphagia scores 3 months and 6 years after surgery (11.1 vs 10.9 , respectively; $P=0.943$ and 8.9 vs 7.6, respectively; $P=0.315) .{ }^{66}$ Shake et $\mathrm{al}^{67}$ reported that the preoperative MRS/WS ratio was $>1.0$ in only $11.1 \%$ of patients with longterm dysphagia after anti-reflux surgery. Therefore, MRS and its 
related indicators could be important factors predicting outcomes following anti-reflux surgeries.

The ideal target of GERD treatment is to reconstruct a normal anti-reflux mechanism. Deprez and Fiasse ${ }^{68}$ prescribed omeprazole (40 g/day for 3-6 months) for patients with GERD and saw significant improvement in esophageal motility. Ravi et a ${ }^{69}$ found that the amplitude of distal esophageal contraction increased significantly after fundoplication in patients with GERD, and that esophageal peristalsis normalized after surgery in patients with either weak peristalsis or ineffective peristalsis before surgery. However, other researchers suggest that combined prokinetic therapy and antireflux surgery does not improve esophageal motility, including resting LES pressure, amplitude of distal esophageal contraction, and incidence of frequent IEM. ${ }^{70}$ Such research groups attest that it is difficult to restore esophageal motility and reconstruct the antireflux mechanism to prevent GERD recurrence.

\section{Conclusion}

With a growing understanding of GERD pathophysiology, there are clearly a number of shortcomings in our knowledge of esophageal motility, the need for intubation, limited examination time, lack of understanding regarding the impact of bolus continuity on esophageal peristalsis, and inability to comprehensively detect esophageal clearance during reflux. Combined 24-hour dynamic manometry and MII monitoring evaluate esophageal motility and reflux events are anticipated to help identify effective methods to treat refractory GERD.

Financial support: This study was supported by National High Technology Research and Development Program of China (No. 2010AA023007).

\section{Conflicts of interest: None.}

Author contributions: Sihui Lin performed the literature search, drafted the article, and revised the article based on the comments of Xiucai Fang and Hua Li; and Xiucai Fang contributed to the study design, revising the article, and final approval to submission to Journal of Neurogastroenterology and Motility.

\section{References}

1. Vakil N, van Zanten SV, Kahrilas P, Dent J, Jones R; Global Consensus Group. The Montreal definition and classification of gastroesophageal reflux disease: a global evidence-based consensus. Am J Gastroenterol 2006;101:1900-1920.

2. Gyawali CP, Roman S, Bredenoord AJ, et al. Classification of esophageal motor findings in gastro-esophageal reflux disease: conclusions from an international consensus group. Neurogastroenterol Motil 2017;29:1-15.

3. Sun X, Ke M, Wang Z, Fang X. [Characteristics of esophageal motility in patients with non-erosive reflux disease and reflux esophagitis.] Zhonghua Yi Xue Za Zhi 2014;94:1718-1721. [Chinese]

4. Schneider JH, Kuper MA, Königsrainer A, Brücher BL. Transient lower esophageal sphincter relaxation and esophageal motor response. J Surg Res 2010;159:714-719.

5. Ergün M, Doğan I, Ünal S. Ineffective esophageal motility and gastroesophageal reflux disease: a close relationship? Turk J Gastroenterol 2012; 23:627-633.

6. Roman S, Holloway R, Keller J, et al. Validation of criteria for the definition of transient lower esophageal sphincter relaxations using highresolution manometry. J Neurogastroenterol Motil 2017;29:1-9.

7. Pandolfino JE, Zhang QG, Ghosh SK, Han A, Boniquit C, Kahrilas PJ. Transient lower esophageal sphincter relaxations and reflux: mechanistic analysis using concurrent fluoroscopy and high-resolution manometry. Gastroenterology 2006;131:1725-1733.

8. Sifrim D, Holloway R, Silny J, Tack J, Lerut A, Janssens J. Composition of the postprandial refluxate in patients with gastroesophageal reflux disease. Am J Gastroenterol 2001;96:647-655.

9. Trudgill NJ, Riley SA. Transient lower esophageal sphincter relaxations are no more frequent in patients with gastroesophageal reflux disease than in asymptomatic volunteers. Am J Gastroenterol 2001;96:2569-2574.

10. Iovino P, Mohammed I, Anggiansah A, et al. A study of pathophysiological factors associated with gastro-esophageal reflux disease in twins discordant for gastro-esophageal reflux symptoms. Neurogastroenterol Motil 2013;25:650-656

11. Kim HI, Hong SJ, Han JP, et al. Specific movement of esophagus during transient lower esophageal sphincter relaxation in gastroesophageal reflux disease. J Neurogastroenterol Motil 2013;19:332-337.

12. Beaumont H, Bennink RJ, de Jong J, Boeckxstaens GE. The position of the acid pocket as a major risk factor for acidic reflux in healthy subjects and patients with GORD. Gut 2010;59:441-451.

13. Zentilin P, Conio M, Mele MR, et al. Comparison of the main oesophageal pathophysiological characteristics between short- and long-segment Barrett's oesophagus. Aliment Pharmacol Ther 2002;16:893-898.

14. Akyüz F, Uyanikoglu A, Ermis F, et al. Gastroesophageal reflux in asymptomatic obese subjects: an esophageal impedance-pH study. World J Gastroenterol 2015;21:3030-3034.

15. Sun XH, Ke MY, Wang ZF, Fang XC. [Role of diaphragmatic crural barrier and esophageal body clearance in patients with gastroesophageal reflux disease.] Zhongguo Yi Xue Ke Xue Yuan Xue Bao 2002;24:289293. [Chinese]

16. Nicodème F, Pipa-Muniz M, Khanna K, Kahrilas PJ, Pandolfino JE. Quantifying esophagogastric junction contractility with a novel HRM topographic metric, the EGJ-contractile Integral: normative values and preliminary evaluation in PPI non-responders. Neurogastroenterol Motil 2014;26:353-360. 
17. Tolone S, De Bortoli N, Marabotto E, et al. Esophagogastric junction contractility for clinical assessment in patients with GERD: a real added value? Neurogastroenterol Motil 2015;27:1423-1431.

18. Rengarajan A, Bolkhir A, Gor P, Wang D, Munigala S, Gyawali CP. Esophagogastric junction and esophageal body contraction metrics on high-resolution manometry predict esophageal acid burden. Neurogastroenterol Motil 2018;30:e13267.

19. Pandolfino JE, Curry J, Shi G, Joehl RJ, Brasseur JG, Kahrilas PJ. Restoration of normal distensive characteristics of the esophagogastric junction after fundoplication. Ann Surg 2005;242:43-48.

20. Pandolfino JE, Shi G, Trueworthy B, Kahrilas PJ. Esophagogastric junction opening during relaxation distinguishes nonhernia reflux patients, hernia patients, and normal subjects. Gastroenterology 2003;125:10181024.

21. Pandolfino JE, Zhang Q, Ghosh SK, Post J, Kwiatek M, Kahrilas PJ. Acidity surrounding the squamocolumnar junction in GERD patients: “acid pocket” versus "acid film”. Am J Gastroenterol 2007;102:26332641.

22. Fletcher J, Wirz A, Young J, Vallance R, McColl KE. Unbuffered highly acidic gastric juice exists at the gastroesophageal junction after a meal. Gastroenterology 2001;121:775-783.

23. Fletcher J, Wirz A, Henry E, McColl KE. Studies of acid exposure immediately above the gastro-oesophageal squamocolumnar junction: evidence of short segment reflux. Gut 2004;53:168-173.

24. Kwiatek MA, Pandolfino JE, Hirano I, Kahrilas PJ. Esophagogastric junction distensibility assessed with an endoscopic functional luminal imaging probe (EndoFLIP). Gastrointest Endosc 2010;72:272-278.

25. Chen JW, Rubenstein JH. Esophagogastric junction distensibility assessed using the functional lumen imaging probe. World J Gastroenterol 2017;23:1289-1297.

26. Weijenborg PW, van Hoeij FB, Smout AJ, Bredenoord AJ. Accuracy of hiatal hernia detection with esophageal high-resolution manometry. Neurogastroenterol Motil 2015;27:293-299.

27. Kahrilas PJ, Bredenoord AJ, Fox M, et al. The Chicago classification of esophageal motility disorders, v3.0. Neurogastroenterol Motil 2015;27:160-174.

28. Tolone S, de Cassan C, de Bortoli N, et al. Esophagogastric junction morphology is associated with a positive impedance-pH monitoring in patients with GERD. Neurogastroenterol Motil 2015;27:1175-1182.

29. Ham H, Cho YK, Lee HH, et al. Esophagogastric junction contractile integral and morphology: two high-resolution manometry metrics of the anti-reflux barrier. J Gastroenterol Hepatol 2017;32:1443-1449.

30. Pandolfino JE, Kim H, Ghosh SK, Clarke JO, Zhang Q, Kahrilas PJ. High-resolution manometry of the EGJ: an analysis of crural diaphragm function in GERD. Am J Gastroenterol 2007;102:1056-1063.

31. Kahrilas PJ, McColl K, Fox M, et al. The acid pocket: a target for treatment in reflux disease? Am J Gastroenterol 2013;108:1058-1064.

32. Spechler SJ, Castell DO. Classification of oesophageal motility abnormalities. Gut 2001;49:145-151.

33. Wu JC, Cheung CM, Wong VW, Sung JJ. Distinct clinical characteristics between patients with nonerosive reflux disease and those with reflux esophagitis. Clin Gastroenterol Hepatol 2007;5:690-695.
34. Jiang L, Ye B, Wang Y, Wang M, Lin L. Esophageal body motility for clinical assessment in patients with refractory gastroesophageal reflux symptoms. J Neurogastroenterol Motil 2017;23:64-71.

35. Ribolsi M, Balestrieri P, Emerenziani S, Guarino MP, Cicala M. Weak peristalsis with large breaks is associated with higher acid exposure and delayed reflux clearance in the supine position in GERD patients. Am J Gastroenterol 2014;109:46-51.

36. Lei WY, Hung JS, Liu TT, Yi CH, Chen CL. Altered oesophageal mechanosensitivity of secondary peristalsis as a pathophysiological marker in patients with globus sensation. Clin Otolaryngol 2018;43:306-311.

37. Chen CL, Yi CH, Liu TT, Orr WC. Effects of mosapride on secondary peristalsis in patients with ineffective esophageal motility. Scand J Gastroenterol 2013;48:1363-1370.

38. Chen CL, Yi CH, Liu TT. Influence of intraluminal acidification on esophageal secondary peristalsis in humans. Dig Dis Sci 2013;58:19481954.

39. Chen CL, Yi CH, Liu TT. Relevance of ineffective esophageal motility to secondary peristalsis in patients with gastroesophageal reflux disease. J Gastroenterol Hepatol 2014;29:296-300.

40. Yi CH, Lei WY, Hung JS, Liu TT, Chen CL, Pace F. Influence of capsaicin infusion on secondary peristalsis in patients with gastroesophageal reflux disease. World J Gastroenterol 2016;22:10045-10052.

41. Schoeman MN, Holloway RH. Integrity and characteristics of secondary oesophageal peristalsis in patients with gastro-oesophageal reflux disease. Gut 1995;36:499-504

42. Page AJ, Blackshaw LA. Roles of gastro-oesophageal afferents in the mechanisms and symptoms of reflux disease. Handb Exp Pharmacol 2009:227-257.

43. Lin S, Li X, Li H, et al. Refractory gastroesophageal reflux disease: pathophysiological basis revealed by 24-hour ambulatory $\mathrm{pH}$-impedancepressure monitoring. Gastroenterology 2016;150:S473.

44. Daum C, Sweis R, Kaufman E, et al. Failure to respond to physiologic challenge characterizes esophageal motility in erosive gastro-esophageal reflux disease. Neurogastroenterol Motil 2011;23:517-e200.

45. Cho YK, Choi MG, Lim CH, et al. Impaired esophageal bolus transit in patients with gastroesophageal reflux disease and abnormal esophageal Acid exposure. Gut Liver 2012;6:440-445.

46. Domingues GR, Winograd R, Lemme EM, et al. Characteristics of oesophageal bolus transport in patients with mild oesophagitis. Eur J Gastroenterol Hepatol 2005;17:323-332.

47. Savarino E, Gemignani L, Pohl D, et al. Oesophageal motility and bolus transit abnormalities increase in parallel with the severity of gastrooesophageal reflux disease. Aliment Pharmacol Ther 2011;34:476-486.

48. Tutuian R, Castell DO. Clarification of the esophageal function defect in patients with manometric ineffective esophageal motility: studies using combined impedance-manometry. Clin Gastroenterol Hepatol 2004;2:230-236.

49. Nguyen NQ, Tippett M, Smout AJ, Holloway RH. Relationship between pressure wave amplitude and esophageal bolus clearance assessed by combined manometry and multichannel intraluminal impedance measurement. Am J Gastroenterol 2006;101:2476-2484.

50. Fornari F, Bravi I, Penagini R, Tack J, Sifrim D. Multiple rapid swal- 
lowing: a complementary test during standard oesophageal manometry. Neurogastroenterol Motil 2009;21:718-e41.

51. Elvevi A, Mauro A, Pugliese D, et al. Usefulness of low- and highvolume multiple rapid swallowing during high-resolution manometry. Dig Liver Dis 2015;47:103-107.

52. Kushnir V, Sayuk GS, Gyawali CP. Multiple rapid swallow responses segregate achalasia subtypes on high-resolution manometry. Neurogastroenterol Motil 2012;24:1069-e561.

53. Martinucci I, Savarino EV, Pandolfino JE, et al. Vigor of peristalsis during multiple rapid swallows is inversely correlated with acid exposure time in patients with NERD. Neurogastroenterol Motil 2016;28:243-250.

54. Martinucci I, de Bortoli N, Savarino E, et al. Esophageal baseline impedance levels in patients with pathophysiological characteristics of functional heartburn. Neurogastroenterol Motil 2014;26:546-555.

55. Frazzoni M, Manta R, Mirante VG, Conigliaro R, Frazzoni L, Melotti $\mathrm{G}$. Esophageal chemical clearance is impaired in gastro-esophageal reflux disease-a 24-h impedance-pH monitoring assessment. Neurogastroenterol Motil 2013;25:399-406.

56. Min YW, Shin I, Son HJ, Rhee PL. Multiple rapid swallow maneuver enhances the clinical utility of high-resolution manometry in patients showing ineffective esophageal motility. Medicine (Baltimore) 2015;94:e1669.

57. Fock KM, Talley N, Goh KL, et al. Asia-Pacific consensus on the management of gastro-oesophageal reflux disease: an update focusing on refractory reflux disease and Barrett's oesophagus. Gut 2016;65:14021415.

58. Eslami O, Shahraki M, Bahari A, Shahraki T. Dietary habits and obesity indices in patients with gastro-esophageal reflux disease: a comparative cross-sectional study. BMC Gastroenterol 2017;17:132.

59. Sun X, Shang W, Wang Z, Liu X, Fang X, Ke M. Short-term and long-term effect of diaphragm biofeedback training in gastroesophageal reflux disease: an open-label, pilot, randomized trial. Dis Esophagus 2016;29:829-836.
60. Maradey-Romero C, Fass R. New and future drug development for gastroesophageal reflux disease. J Neurogastroenterol Motil 2014;20:6-16.

61. Kessing BF, Smout AJ, Bennink RJ, Kraaijpoel N, Oors JM, Bredenoord AJ. Prucalopride decreases esophageal acid exposure and accelerates gastric emptying in healthy subjects. Neurogastroenterol Motil 2014;26:1079-1086.

62. Ndraha S. Combination of PPI with a prokinetic drug in gastroesophageal reflux disease. Acta Med Indones 2011;43:233-236.

63. Nennstiel S, Bajbouj M, Schmid RM, Becker V. Prucalopride reduces the number of reflux episodes and improves subjective symptoms in gastroesophageal reflux disease: a case series. J Med Case Rep 2014;8:34.

64. Yamashita H, Kanamori A, Fukuchi T, et al. Novel prokinetic acotiamide reduces transient lower esophageal sphincter relaxation in healthy subjects. Digestion 2015;92:90-98.

65. Seo KW, Park MI, Yoon KY, Park SJ, Kim SE. Laparoscopic partial fundoplication in case of gastroesophageal reflux disease patient with absent esophageal motility. J Gastric Cancer 2015;15:127-131.

66. Broeders JA, Sportel IG, Jamieson GG, et al. Impact of ineffective oesophageal motility and wrap type on dysphagia after laparoscopic fundoplication. Br J Surg 2011;98:1414-1421.

67. Shaker A, Stoikes N, Drapekin J, Kushnir V, Brunt LM, Gyawali CP. Multiple rapid swallow responses during esophageal high-resolution manometry reflect esophageal body peristaltic reserve. Am J Gastroenterol 2013;108:1706-1712.

68. Deprez P, Fiasse R. Healing of severe esophagitis improves esophageal peristaltic dysfunction. Dig Dis Sci 1999;44:125-133.

69. Ravi N, Al-Sarraf N, Moran T, et al. Acid normalization and improved esophageal motility after Nissen fundoplication: equivalent outcomes in patients with normal and ineffective esophageal motility. Am J Surg 2005;190:445-450.

70. Xu JY, Xie XP, Song GQ, Hou XH. Healing of severe reflux esophagitis with PPI does not improve esophageal dysmotility. Dis Esophagus 2007;20:346-352. 